\title{
K\&C suspension parameters stability by production tolerances
}

\author{
Vladislav Borisenko*, Artem Kiselev, Luis Leoro, Aleksei Borovkov and Yury Boldyrev \\ Peter the Great St. Petersburg Polytechnic University, St. Petersburg, Russian Federation
}

\begin{abstract}
This paper considers a modern approach of K\&C parameters stability analysis using the suspension MBS model of a short-wheelbase electric vehicle. According to the results of the work, even minor errors in suspension hardpoints positioning when overlaying can greatly affect the K\&C parameters of car suspensions. Using MBS models, quasi-static K\&C events have been simulated. In the same way the dependences of the suspension K\&C parameters are numerically determined. Moreover, these calculations were made with different hardpoints positions for joints of wishbones fastening on a frame, and joint of a steering rod with a steering rack. The influence of suspension hardpoints displacement on the K\&C parameters of the vehicle was estimated. As a result, recommendations are made for production positioning tolerances of suspension hardpoints in order to avoid deterioration of K\&C parameters. Basically, the appearance of inaccuracies in the positioning of hardpoints leads to critical changes in anti-dive, anti-lift, kingpin inclination angle, bump camber and bump steer parameters.
\end{abstract}

\section{Introduction}

Car suspension is a very complex mechanical system. Design of kinematic suspension scheme is used to determine the position of the fasteners of the suspension elements (hardpoints) [1-3]. Furthermore geometric dimensions and position of the suspension hardpoints (calculated positions of joints and bushings centers) affect the K\&C parameters of the suspension, which determine the handling, stability and patency of the vehicle [4-12]. Firstly, at the stage of designing a new chassis scheme, the required K\&C parameters are laid. Secondly, according to the parameters geometric dimensions and the position of the hardpoints are selected. What is more a list of defining K\&C parameters and allowable limits is set even before the start of design. Experience shows that the number of such parameters can be more than 50 for each suspension type.

Above all experience shows that any, even

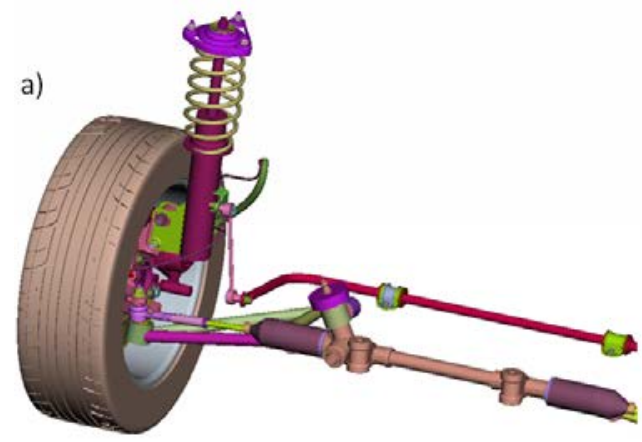

insignificant, shift of the hardpoint of the suspension can lead to a change in the parameter beyond the permissible limits. In particular, during the production of the car, the hardpoints may be shifted due to inaccuracy in the manufacture of parts. Moreover: the smaller the tolerances in the manufacture of parts, the higher its cost.

Therefore, it becomes urgent to assess the stability of the selected K\&C parameters of the suspension depending on the displacements of the structural units that may be caused by manufacturing errors. Thus, the problem arises of determining the permissible value and direction of hardpoint displacements, and unacceptable displacements that lead to the $\mathrm{K} \& \mathrm{C}$ parameters of the suspension going beyond the indicated limits.

The study of these dependencies was carried out using an example of a short-base passenger electric car with a double wishbone rear suspension (Fig. 1a) and a MacPherson-type front suspension (Fig. 1b).

Accordingly to calculate the K\&C parameters of the suspensions, MBS models of these suspensions are

Fig. 1. Scheme front (a) and rear (b) suspension.

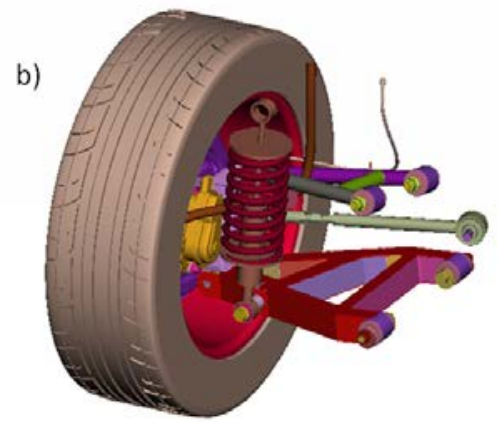

\footnotetext{
* Corresponding author: borisenko@compmechlab.ru
} 
created. Using them, the dependences of the suspension parameters during breakdown, rebound, or when turning the wheel are numerically determined. According to the obtained dependencies, in turn, the K\&C parameters are determined.

\section{Methods}

\subsection{The basics of MBS modeling}

The main idea of MBS modeling is based on the numerical integration of the Lagrange equations of the second kind of a mechanical system, implemented in the MSC.ADAMS software package. The Lagrange equations themselves have the form[13]:

$$
\left\{\begin{array}{c}
M \ddot{q}+\varphi_{q}^{T} \lambda-A^{T} F(q, \dot{q})=0 \\
\varphi(q, t)=0
\end{array},\right.
$$

where $\mathrm{M}$ is an inertial matrix, $\mathrm{q}$ is a column matrix of the Lagrange coordinates characterizing movements, $\mathrm{F}$ is a column matrix of external forces, $\varphi$ is a set of constraints, $\mathrm{A}^{\mathrm{T}}$ is a matrix of the external forces projected onto direction q; $\varphi_{\mathrm{q}}$ is a gradient of constraints.

$$
\begin{aligned}
& \varphi(\dot{q}, q, t)=\varphi_{q}(q, t) \dot{q}-v(q, t)=0 \\
& \varphi(\ddot{q}, \dot{q}, q, t)=\varphi_{q} \varphi(\ddot{q}, \dot{q}, q, t)= \\
& =\varphi_{q}(\dot{q}, t) \ddot{q}-\eta(q, \dot{q}, t)=0
\end{aligned}
$$

where $v(q, t)=-\varphi_{t}(q, t)$ is the velocity vector, and $\eta(q, \dot{q}, t)=-\left(\varphi_{q} \dot{q}\right)_{q} \dot{q}-2 \varphi_{q t} \dot{q}-\varphi_{t t} \quad$ is the acceleration vector.

Define the initial conditions:

$$
\begin{aligned}
& q(0)=0 \\
& \dot{q}(0)=0
\end{aligned}
$$

Equations (1) - (3) uniquely determine the motion of solids.

One of the most effective algorithms for solving multi-mass systems is the technology implemented in the MSC.ADAMS / Solver software package, differential equations are integrated numerically by Runge-Kutta methods, as well as direct and inverse Euler methods. Bringing a system of algebraic nonlinear equations characterizing the relations in the system under consideration:

$$
\begin{aligned}
& (x)=0, \quad F(x)=\left(f_{1}(x), f_{2}(x), \ldots, f_{n}(x)\right)^{T}, \\
& f_{i} \in \mathrm{p}^{1}, x \in R^{n}
\end{aligned}
$$

Having linearized system (5), we obtain, retaining the linear terms

$$
F(x)=F\left(x^{0}\right)+F^{\prime}\left(x^{0}\right)\left(x-x^{0}\right)+o\left(\left\|x-x^{0}\right\|\right)
$$

Where the matrix of derivatives has the standard form

$$
F^{\prime}(x)=\frac{\partial F(x)}{\partial x}=\left[\begin{array}{ccc}
\frac{\partial f_{1}(x)}{\partial x_{1}}, & \ldots & \frac{\partial f_{1}(x)}{\partial x_{n}} \\
\cdots & \ldots & \ldots \\
\frac{\partial f_{n}(x)}{\partial x_{1}}, & \ldots & , \frac{\partial f_{n}(x)}{\partial x_{n}}
\end{array}\right]
$$

Then the Newton-Raphson method for solving the resulting system (5) has the following standard form:

$$
x^{k+1}=x^{k}-\left[F^{\prime}\left(x^{k}\right)\right]^{-1} F\left(x^{k}\right)
$$

\subsection{MBS models front and rear suspension}

MBS models of front and rear suspensions were implemented, as indicated, in the MSC.ADAMS software package. Above all elements of the model have mass-inertial characteristics and are connected to each other at the hardpoints of the suspension [14-17]. In addition the type and composition of the considered models is presented in Fig. 2. The MacPherson type front suspension has 20 key points (excluding steering). Taking into account symmetry, one half of the suspension has 10 independent hardpoints (Fig. 2a). The connection points between the lower wishbone and the subframe are designated as hardpoints 1 and 2, the connection point of the lower wishbone and the upright is 3 , the shock absorber strut points are 4 and 5 , the stabilizer mount point to the subframe is 6 , the stabilizer strut points are 7 and 8 , the steering point traction - 9 and 10.

The double wishbone rear suspension has 20 key points. Given symmetry, one half of the rear suspension has 10 independent anchor points (Fig. 2b). The connection points between the lower arm and subframe are designated as hardpoints 1 and 2, the connection point of the lower arm and upright is 3, the connection points between the upper wishbone and subframe are 4 and 5 , the connection point of the upper wishbone and upright is 6 , the shock absorber points are 7 and 8 , tie rod points - 9 and 10. Mutual arrangement of hardpoints affects the operational characteristics of the suspension. Based on the suspension models, some quasi-static K\&C events have been simulated in ADAMS/Car [18]:

- Vertical motion - A displacement controlled parallel wheel movement over a specified jounce interval (max jounce / max rebound movement).

- Roll motion - A displacement controlled vehicle body rotation over a specified roll interval $( \pm$ max roll movement). Wheel movements are prevented vertically. 

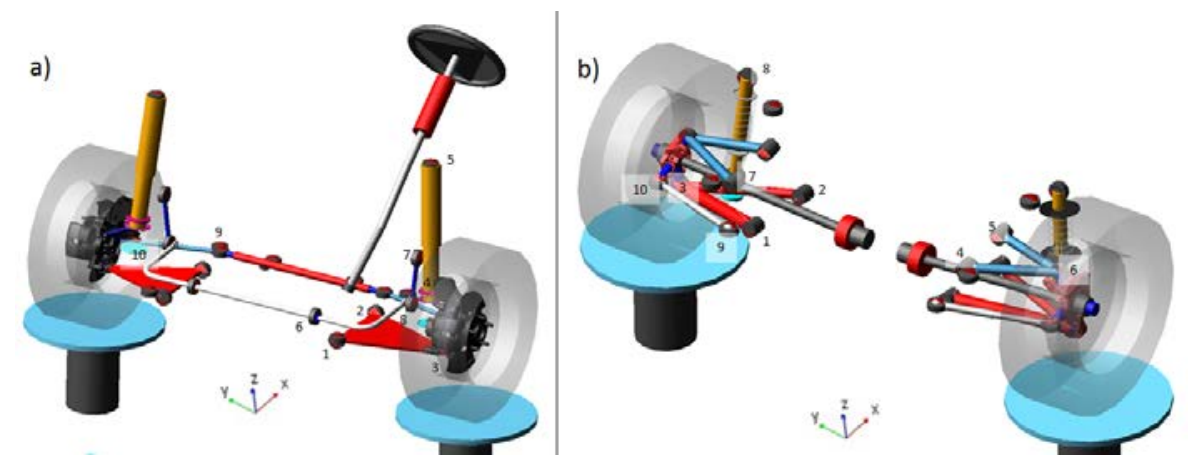

Fig. 2. MBS models of the front (a) and rear (b) suspension.
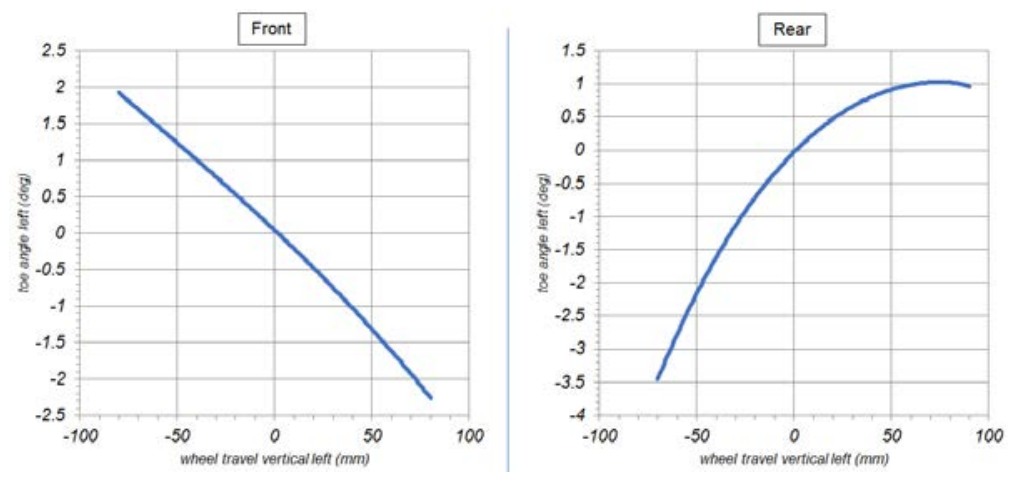

Fig. 3. Dependence of the toe angle on the vertical wheel travel for front and rear suspension.
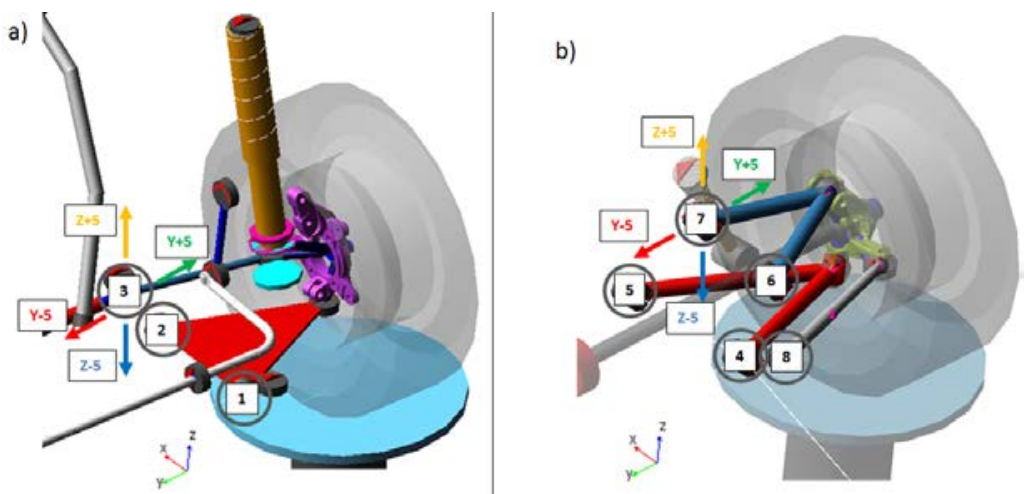

Fig. 4. Variable points of the front (a) and rear (b) suspension.

- Lateral force (opposite) - A force controlled lateral movement of the wheel. The forces are applied in antiphase (counteracting laterally) at ground level.

- Drive force - A force controlled longitudinal movement of the wheel. The force is applied in the wheel center in order to resemble propulsive forces acting on the suspension.

- Brake force - A force controlled longitudinal movement of the wheel. The force is applied at ground level in order to resemble brake forces acting on the suspension.

- Steer motion - A displacement controlled movement of the steering rack. The movement corresponds to a specified steering wheel angle interval ( \pm max steering wheel angle).

In addition the dependences of the suspension parameters during quasi-static events are determined using the constructed MBS models. For example, Fig. 3

shows the dependence between toe angle and vertical position of the wheel. Correspondingly K\&C parameters $[19,20]$ are further calculated, as shown in Table. 1.

\subsection{K\&C suspension parameters stability}

Above all, MBS calculations were performed with a change in the coordinates of the suspension hardpoints to assess the impact of errors during assembly of the car on the deterioration of the $\mathrm{K} \& \mathrm{C}$ parameters of the suspension of a vehicle. However to consider the mutual displacement of each point in all directions, more than 1 billion calculations will be required to determine the parameters for each suspension. Consequently, obtaining a significant correlation in this case will require significant resources. Therefore, in this work, we considered the key points most susceptible to 
Table 1. Defined K\&C parameters with specified limits.

\begin{tabular}{|c|c|c|}
\hline K\&C parameter & Front susp. & Rear susp. \\
\hline Off Center Steering Ratio, ${ }^{\circ}{ }^{\circ}$ & $15 \div 17$ & - \\
\hline 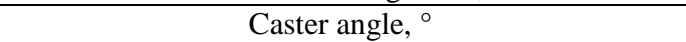 & $5.0 \div 10.0$ & - \\
\hline KPI (kingpin inclination angle), ${ }^{\circ}$ & $12 \div 16$ & - \\
\hline Scrub Radius, mm & $-15 \div 5$ & - \\
\hline Castor trail, $\mathrm{mm}$ & $<45$ & - \\
\hline Steer Axis Offset Lateral, mm & $<70$ & - \\
\hline Steer Axis Offset Longitudinal, mm & $-3 \div 3$ & - \\
\hline Percent Ackerman 40\% steering angle, \% & $>33 \%$ & - \\
\hline Ackerman error at max steering inner wheel, ${ }^{\circ}$ & $<3.5$ & - \\
\hline Outside Turn Diameter, $\mathrm{m}$ & $<8.5$ & - \\
\hline Bump travel $2 * \mathrm{GVM}, \mathrm{mm}$ & $72 \div 80$ & $77 \div 87$ \\
\hline Maximum rebound travel up to $\mathrm{Fz}=0, \mathrm{~mm}$ & $-95 \div-85$ & $-75 \div-68$ \\
\hline Bump Steer, \%/m & $-25 \div-3.5$ & $0,5 \div 25$ \\
\hline Bump Camber, \%/m & $-19 \div-3$ & $-23 \div-15$ \\
\hline 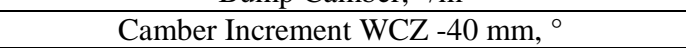 & $0 \div 1$ & - \\
\hline 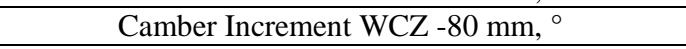 & $0.7 \div 2$ & - \\
\hline 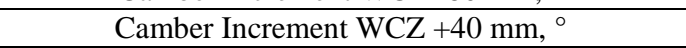 & $-1.5 \div-0.3$ & - \\
\hline 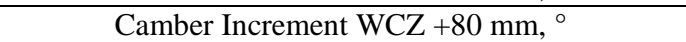 & $-2.0 \div-0.4$ & - \\
\hline Bump Castor, $\% / m$ & $11 \div 22$ & - \\
\hline Bumpstop attack length, mm & $10 \div 32$ & $>25$ \\
\hline Roll center height vertical displacement $20 \mathrm{~mm}, \mathrm{~mm}$ & $-55 \div 0$ & $-40 \div 0$ \\
\hline Roll center height vertical displacement $-20 \mathrm{~mm}, \mathrm{~mm}$ & $0 \div 55$ & $0 \div 40$ \\
\hline Total Roll Stiffness, $\mathrm{Nm} /{ }^{\circ}$ & $500 \div 1300$ & $400 \div 1050$ \\
\hline Roll Center Height, $\mathrm{mm}$ & $60 \div 152$ & $110 \div 250$ \\
\hline Roll center Lateral migration 2 deg of roll, mm & $-200 \div 200$ & - \\
\hline Roll center Vertical migration 2 deg of roll, mm & $-10 \div 10$ & $-1 \div 140$ \\
\hline Roll Steer, $\%$ & $-0,3 \div-0,04$ & $0,025 \div 1$ \\
\hline Body Roll Camber, ${ }^{\circ}{ }^{\circ}$ & $-0,8 \div-0,12$ & $-0.33 \div 0$ \\
\hline
\end{tabular}

displacement during the production and assembly of the car, and also which do not have the ability to adjust after assembly. Among them: the point of attachment of the wishbones on the frame, as well as the point of connection of the steering link with the steering rack. So for the front suspension, these are points 1,2,9 in Fig. 2a, for the rear suspension - points 1,2,4,5,9 in Fig. 2b.

In fact to find the critical displacements of the suspension points, changes in their coordinates by \pm 5 $\mathrm{mm}$ along one axis were considered. Changes occur in two directions: $\mathrm{Y}$ or $\mathrm{Z}$. The displacement along the longitudinal axis $\mathrm{X}$ was not considered due to the small effect on the K\&C parameters. Thus, for each point, 5 possible positions are determined: initial, shifted to the left $(y-5)$, shifted to the right $(y+5)$, raised vertically $(z+$ 5 ), dropped vertically (z-5). In Fig. 4 below are selected suspension points and their displacements are illustrated.

Thus, for the front suspension, 125 options for the relative positioning of hardpoints are considered, and for the rear suspension - 3125 .

\section{Results and Discussion}

As a result, options for changing the position of hardpoints were selected, which led to the K\&C parameters exceeding the indicated limits in Table 2. For the front suspension, these are 37 options for changing the position of the points, for the rear suspension - 2641.

Critical point distributions were selected according to groups of options that correlate with each other in the direction of the points' movements. Thus, correlations were found between the direction of movement of the suspension points and the deterioration of the $\mathrm{K} \& \mathrm{C}$ parameters.

As a result, the following dependences of the deterioration of the K\&C parameters on the direction of displacement of the hardpoints were obtained for the front suspension (point numbers are indicated according to Fig. 4):

- simultaneous displacement more than two hardpoints leads to going beyond a large number of K\&C parameters specified limits;

- shifting the angle of inclination of the axis in the horizontal plane (1: Y-5; 2: Y +5 ) leads to a deterioration in the anti-dive parameter;

- simultaneous horizontal displacement of the lever front point (1: Y-5) and the lever vertical point of the lever $(2: Z+5)$ leads to a critical change in the bump steer, roll steer, anti-dive parameters;

- simultaneous shift of the front point of the lever vertically (1: $Z \pm 5)$ and the rear point of the lever horizontally (2: $\mathrm{Y} \pm 5$ ) leads to a critical change in the bump steer, roll steer, anti-dive, anti-lift parameters.

For the rear suspension, the following patterns were identified:

- simultaneous displacement of three or more selected points leads to going beyond a large number of K\&C parameters specified limits;

- simultaneous shift of the front point of the upper arm horizontally (6: $Y \pm 5$ ) and the rear point of the 
Table 2. Variants of distribution of points for which indicators are outside the specified limits.

\begin{tabular}{|c|c|c|c|c|c|c|c|c|}
\hline K\&C parameter & \multicolumn{4}{|c|}{ Front susp. } & \multicolumn{4}{|c|}{ Rear susp. } \\
\hline Off Center Steering Ratio, ${ }^{\circ}{ }^{\circ}$ & №1 & №2 & $\ldots$ & №37 & №1 & №2 & $\ldots$ & №2641 \\
\hline Caster angle, $^{\circ}$ & 15.9 & 15.9 & $\ldots$ & 15.9 & & & & \\
\hline $\begin{array}{l}\text { KPI (kingpin inclination } \\
\text { angle), }{ }^{\circ}\end{array}$ & 5.29 & 5.29 & $\cdots$ & 5.29 & & & & \\
\hline Scrub Radius, mm & 13.2 & 13.2 & $\ldots$ & 13.2 & & & & \\
\hline Castor trail, $\mathrm{mm}$ & 3.6 & 3.6 & $\ldots$ & 3.7 & & & & \\
\hline Steer Axis Offset Lateral, mm & 28.8 & 28.8 & $\ldots$ & 28.8 & & & & \\
\hline $\begin{array}{c}\text { Steer Axis Offset } \\
\text { Longitudinal, mm }\end{array}$ & 67.6 & 67.6 & ... & 67.7 & & & & \\
\hline $\begin{array}{l}\text { Percent Ackerman } 40 \% \\
\text { steering angle, \% }\end{array}$ & 2.3 & 2.3 & $\ldots$ & 2.3 & & & & \\
\hline $\begin{array}{l}\text { Ackerman error at max } \\
\text { steering inner wheel, }{ }^{\circ}\end{array}$ & 46.0 & 46.0 & .... & 46.0 & & & & \\
\hline Outside Turn Diameter, $\mathrm{m}$ & 3.2 & 3.2 & $\ldots$ & 3.2 & & & & \\
\hline Bump travel 2*GVM, mm & 8.6 & 8.5 & $\ldots$ & 8.6 & & & & \\
\hline $\begin{array}{l}\text { Maximum rebound travel up } \\
\text { to } \mathrm{Fz}=0, \mathrm{~mm}\end{array}$ & 80.0 & 79.9 & ... & 79.9 & 94.67 & 94.67 & $\ldots$ & 93.50 \\
\hline Bump Steer, $\%$ m & -89.1 & -89.2 & $\ldots$. & -89.2 & -70.00 & -67.19 & $\ldots$. & -69.58 \\
\hline Bump Camber, $\% / \mathrm{m}$ & -30.4 & -31.2 & $\ldots$ & -30.1 & 60.87 & 60.87 & $\ldots$ & 55.91 \\
\hline $\begin{array}{c}\text { Camber Increment WCZ -40 } \\
\text { mm, }{ }^{\circ}\end{array}$ & -17.4 & -17.4 & $\ldots$ & -17.2 & 66.32 & 66.32 & $\ldots$ & 68.78 \\
\hline $\begin{array}{c}\text { Camber Increment WCZ -80 } \\
\text { mm, }{ }^{\circ}\end{array}$ & 0.86 & 0.87 & ... & 0.86 & & & & \\
\hline $\begin{array}{c}\text { Camber Increment WCZ +40 } \\
\text { mm, }{ }^{\circ}\end{array}$ & 2.04 & 2.05 & .... & 2.03 & & & & \\
\hline $\begin{array}{l}\text { Camber Increment WCZ +80 } \\
\text { mm, }{ }^{\circ}\end{array}$ & -0.51 & -0.51 & $\cdots$ & -0.50 & & & & \\
\hline Bump Castor, $\% / \mathrm{m}$ & -0.60 & -0.60 & $\ldots$ & -0.57 & & & & \\
\hline Bumpstop attack length, mm & 11.4 & 11.6 & $\ldots$ & 13.0 & 44.42 & 46.82 & $\ldots$ & 46.01 \\
\hline $\begin{array}{l}\text { Roll center height vertical } \\
\text { displacement } 20 \mathrm{~mm}, \mathrm{~mm}\end{array}$ & 23.2 & 23.2 & $\cdots$. & 23.2 & -17.10 & -6.43 & $\ldots$ & -3.59 \\
\hline $\begin{array}{l}\text { Roll center height vertical } \\
\text { displacement }-20 \mathrm{~mm}, \mathrm{~mm}\end{array}$ & 51.2 & 51.6 & $\cdots$ & 51.9 & 15.01 & -0.94 & $\ldots$ & -4.79 \\
\hline Total Roll Stiffness, $\mathrm{Nm} /{ }^{\circ}$ & 552.9 & 552.9 & $\ldots$ & 552.8 & 407.6 & 379.3 & $\ldots$ & 290.0 \\
\hline Roll Center Height, mm & 147.5 & 148.6 & $\ldots$. & 145.4 & 79.29 & 27.96 & $\ldots$. & -97.39 \\
\hline $\begin{array}{c}\text { Roll center Lateral migration } 2 \\
\text { deg of roll, mm }\end{array}$ & -8.4 & -8.5 & .... & -8.9 & -47.95 & -9.32 & .... & -206.3 \\
\hline $\begin{array}{l}\text { Roll center Vertical migration } \\
2 \text { deg of roll, mm }\end{array}$ & -0.32 & -0.33 & .... & -0.31 & -0.12 & -0.24 & $\cdots$ & 0.64 \\
\hline Roll Steer, ${ }^{\circ}{ }^{\circ}$ & -0.20 & -0.20 & $\ldots$ & -0.20 & 0.96 & 1.42 & $\ldots$ & 3.69 \\
\hline Body Roll Camber, ${ }^{\circ}{ }^{\circ}$ & -0.11 & -0.11 & $\ldots$ & -0.11 & 1.24 & 1.60 & $\ldots$ & 3.13 \\
\hline
\end{tabular}

upper arm vertically (7: $Z+5)$ leads to a critical change in the bump steer, bump camber parameters;

- simultaneous shift of the front point of the upper arm horizontally $(6: Y+5)$ and the rear point of the upper arm horizontally (7: $\mathrm{Y} \pm 5$ ) leads to a critical change in the bump camber parameter;

- the simultaneous shift of the front point of the upper arm vertically $(6: Z+5)$ and the rear point of the upper arm horizontally (7: $\mathrm{Y} \pm 5$ ) also leads to a critical change in the bump camber parameter;

- the vertical lifting points of the upper arm (6: $\mathrm{Z}+$ 5, $7: Z+5$ ) leads to a critical change of the kingpin inclination angle parameter;

- simultaneous shift of the front point of the lower arm horizontally (4: $\mathrm{Y} \pm 5$ ) and the rear point of the lower arm vertically and horizontally (5: $Y \pm 5, Z+5)$ leads to a critical change of the bump camber, bump steer, kingpin inclination angle, anti-lift angle and roll stiffness parameters;

- simultaneous vertical displacement of the lower arm front point (4: $\mathrm{Z} \pm 5$ ) and opposite displacement of the lower arm rear point (5: $Z \bar{\mp} 5$ ) leads to a critical change in the anti-lift angle parameters;

- vertical displacement of the inner point of the guide lever leads to a critical change in the toe angle parameter;

- simultaneous displacement of the front or rear points of different wishbones in one direction leads to critical changes in the roll center height parameter.

\section{Conclusions}

To summarise, the sensitivity of $\mathrm{K} \& \mathrm{C}$ parameters was estimated depending on the displacements of the suspension hardpoints by $5 \mathrm{~mm}$ along the vertical and 
horizontal axes. In addition, the calculaton was based on the MBS models of electric vehicle suspensions (MacPherson - front, double wishbone - rear).

Hence, it was found that even small positioning errors that may occur during production can greatly affect the predetermined design K\&C parameters.

Finally, according to the results, dependencies were found between the change in the position of the hardpoints and the deterioration of the parameters. The following recommendations can be deduced from them:

At the front suspension:

- the front suspension has poor sensitivity to the displacement of the selected wishbone points, the displacement of one nodal point will not lead to critical changes in the K\&C parameters;

- it is recommended not to allow the displacement of the inner point of the steering link up along the vertical axis;

- it is recommended not to allow displacement of the angle of inclination of the wishbone axis in the horizontal plane.

At the rear suspension:

- during assembly, prevent the points of one of the wishbones from shifting in opposite directions along the $\mathrm{Y}$ or $\mathrm{Z}$ axis, thereby changing the angle of the wishbone mount by more than 1 degree;

- during assembly, do not allow the displacement of the front or rear points on different wishbones in opposite directions along the $\mathrm{Y}$ or $\mathrm{Z}$ axis;

- during assembly, do not allow displacement of the internal hardpoint of the tierod along the $\mathrm{Z}$ axis.

\section{Acknowledgements}

This work was performed within the implementation of Federal Targeted Program for Research and Development in Priority Areas of Development of the Russian Scientific and Technological Complex for 20142020, the project «Creation of Smart Digital Twin and Preproduction Prototype of Small-Size Urban Electric Car with ADAS 3-4 Level System» (Agreement № 05.578.21.0269, the unique project identifier is RFMEFI57818X0269).

\section{References}

1. X. Liu, J. Luo, Y. Wang, H. Guo, and X. Wang, Res. J. Appl. Sci. Eng. Technol. 06, 4569 (2013)

2. P. E. Pfeffer, M. Harrer, and D. N. Johnston, Veh. Syst. Dyn. 46, 413 (2008)

3. H. Wang, S. Wang, and M. M. Tomovic, J. Mech. Sci. Technol. 23, 100 (2009)

4. J. Z. Feng, J. T. Song, and W. H. Zhu, Appl. Mech. Mater. 120, 375 (2011)

5. A. Rahmani Hanzaki, S. K. Saha, and P. V. M. Rao, Multibody Syst. Dyn. 21, 325 (2009)

6. W. C. Mitchell, R. Simons, T. Sutherland, and M. Keena-Levin, in SAE Tech. Pap. (2008)

7. P. Morse, in SAE Tech. Pap. (2004)
8. M. C. Popescu, C. A. Bulucea, and L. PerescuPopescu, in Proc. 8th WSEAS Int. Conf. Educ. Educ. Technol. EDU '09 (2009)

9. H. S. Sohn, H. W. Shin, and H. W. Lee, in SAE Tech. Pap. (1998)

10. D. Xu, B. Zhu, S. Hu, Z. Zhang, B. Wang, W. Chen, and Y. Xu, in Lect. Notes Electr. Eng. pp. 487-494 (2013)

11. J. Warfford and N. Frey, in SAE Tech. Pap. (2004)

12. Y. Yang, Y. Li, Z. Yue, C. Wang, M. Chen, J. Chen, G. Chen, and J. Bai, in Lect. Notes Electr. Eng. pp. 339-351 (2013)

13. W. Ren, S. Huang, and J. Zhang, in Syst. Model. Simul. (Springer Japan, Tokyo,), pp. 188-192 (2007)

14. J. Zhang, X. Jia, Z. Zhao, and R. Gao, in 2015 Int. Conf. Comput. Sci. Mech. Autom. (IEEE), pp. 297301 (2015)

15. S. Sleesongsom and S. Bureerat, in Lect. Notes Comput. Sci. (Including Subser. Lect. Notes Artif. Intell. Lect. Notes Bioinformatics) pp. 612-623 (2018)

16. J. H. Liang and L. L. Xin, Appl. Mech. Mater. 128129, 34 (2011)

17. Z. L. Liao, G. B. Yang, C. G. Liu, and B. Bin Pang, Appl. Mech. Mater. 299, 23 (2013)

18. T. Shim and P. C. Velusamy, Int. J. Veh. Des. 43, 258 (2007) J

19. . C. Dixon, Suspension Geometry and Computation (John Wiley \& Sons, Ltd, Chichester, UK, 2009)

20. J. Zhan, J. L. Lu, and X. Guan, Appl. Mech. Mater. 278-280, 14 (2013) 